\title{
Genetic Diversity in Cynara cardunculus Determined by Sequence-related Amplified Polymorphism Markers
}

\author{
Vanina Cravero ${ }^{1}$ \\ CONICET, CC14, Zavalla, Sante Fe S2125ZAA, Argentina
}

\begin{abstract}
Eugenia Martín and Enrique Cointry
Genetics and Plant Breeding, Universidad Nacional de Rosario, CC 14 (S2125ZAA) Zavalla, Santa Fe, Argentina
\end{abstract}

\begin{abstract}
AdDitional INDEX words. globe artichoke, cardoon, genetic resources, genetic diversity, DNA-based markers, DNA polymorphism

Abstract. Twenty-six wild and cultivated accessions of cardoon [Cynara cardunculus L. var. sylvestris (Lam.) Fiori and $C$. cardunculus var. cardunculus L., respectively] and globe artichoke [C. cardunculus var. scolymus (L.) Fiori] were analyzed to evaluate genetic diversity using sequence-related amplified polymorphism (SRAP) markers. Eleven qualitative and quantitative traits were evaluated and euclidean distances among genotypes were calculated. A total of 15 primer pairs were initially assayed and seven of them were finally selected as a result of their consistent amplification together with the clear banding patterns obtained. Genetic distances were calculated according to standardized Jaccard's distance index. Both matrices were subjected to cluster analysis. Dendrograms showed that cardoons were clearly separated from artichoke. These results showed that SRAP markers will be useful tools for studying genetic diversity in $C$. cardunculus.
\end{abstract}

Globe artichoke (Cynara cardunculus var. scolymus) originated in the Mediterranean basin, where another two botanical varieties are present: C. cardunculus var. cardunculus (the cultivated cardoon) and C. cardunculus var. sylvestris (the wild progenitor of globe artichoke). Artichoke propagation is mainly by vegetative means, but a high number of cultivars or ecotypes around the world (sometimes the same cultivar) have different names according to the region of cultivation (Sonnante et al., 2002).

An understanding of the magnitude and patterns of genetic diversity in crop plants has important implications for breeding programs and for conservation of genetic resources. Estimating the level of genetic diversity is of paramount importance for germplasm enhancement and for obtaining future genetic gain. Several authors analyzed the variability among cultivated and wild artichoke accessions using morphologic traits (Asprelli et al., 2001; Dellacecca et al., 1976; Elia and Miccolis, 1996; Miccolis et al., 1989; Porceddu et al., 1976). Comparative morphology suggested close relationships between globe artichoke and cardoon (Wiklund, 1992). More recently, cytogenetic test and isozyme comparisons (Rottemberg et al., 1996) confirmed this notion. Only a few molecular analyses have been conducted in this species. Lanteri et al. (2001), Sonnante et al. (2002), and Tivang et al. (1996) evaluated genetic diversity in artichoke using randomly amplified polymorphic DNA (RAPD) markers; Pagnotta et al. (2004) applied amplified fragments length polymorphisms (AFLPs) and inter-simple sequence repeats (ISSRs) to reveal variation within the 'Romanesco' population, and simple sequence repeat (SSR) markers

Received for publication 27 Apr. 2006. Accepted for publication 28 Sept. 2006. We thank Ing. Agr. F. López Anido for providing plant material and Dr. C. Quiros for critical reading of the manuscript.

${ }^{1}$ Corresponding author. E-mail: vcravero@unr.edu.ar. were recently developed in globe artichoke by Acquadro et al. (2003, 2005).

These kinds of markers could be used for germplasm evaluation. Each one has its own advantages and disadvantages. RAPD markers provide a simple polymerase chain reaction (PCR)-based molecular tool for the evaluation of genetic variation, but they have poor consistency and low reproducibility (Roodt et al., 2002; Welsh and McClelland, 1990). SSRs have the advantage of producing mostly codominant markers; however, their development is expensive and time-consuming (Li and Quiros, 2001). AFLPs are now widely used for genomic fingerprinting (Karaca et al., 2002; Zhang et al., 1999) as a result of their high multiplexing ratio (Vos et al., 1995). However, AFLPs are complex, require multiple steps, and have pseudopolymorphism when methylation-sensitive restriction enzymes are used (Li and Quiros, 2001).

Sequence-related amplified polymorphism (SRAP) technology has been recognized as a new and useful molecular marker system for mapping and gene tagging in Brassica oleracea L. (Li and Quiros, 2001), Cucurbita moschata (Duchesne ex Lam.) Duchesne ex Poir (Ferriol et al., 2004), and Buchloe dactyloides (Nutt.) Englem. (Budak et al., 2004). It targets coding sequences and can result in the identification of a number of codominant markers. SRAPs are based on twoprimer amplification in which the primers are 17 or 18 nucleotides long. Primers consist of a core sequence of 13 or 14 bases in which the $5^{\prime}$-most 10 or 11 bases are nonspecific followed by the sequence CCGG in the forward primer and AATT in the reverse one. The core sequences are followed by three selective nucleotides at the $3^{\prime}$ end of each primer (Li and Quiros, 2001). SRAPs are more reproducible than RAPDs and less complicated than AFLPs (Budak et al., 2004).

The objectives of this research were to determine if SRAP markers could be used to evaluate genetic diversity in a 
C. cardunculus collection and to reveal the genetic distances between artichoke cultivars and wild and cultivated cardoons.

\section{Materials and Methods}

Seventeen genotypes of $C$. cardunculus var. scolymus, that represent the variability in globe artichoke, five genotypes of C. cardunculus var. cardunculus and four genotypes of C. cardunculus var. sylvestris (collected in different places in Argentina and Uruguay), were propagated in the Experimental Station of the Universidad Nacional de Rosario at Zavalla, Argentina (Table 1).

The morphologic characterization of 10 plants per accession was accomplished during the spring season. Nine quantitative traits (height and diameter of the plant; number of capitula per plant; weight, length, and diameter of the main capitulum; weight, length, and diameter of secondary capitula) and two qualitative traits (capitulum color and spine presence) were evaluated. Color was measured on a qualitative scale: $1=$ green, 2 = purple-green, and 3 = purple (Asprelli et al., 2001). For spine presence, two categories were established: $1=$ spiny capitula and $2=$ spineless capitula.

Genomic DNA was extracted from fresh leaves of each globe artichoke accession using the PureLink Plant Total DNA Purification Kit (Invitrogen, Carlsbad, Calif.). A total of 15 primer pairs were assayed on the 26 accessions. Primer banding patterns that were difficult to score and those that failed to amplify consistently in all genotypes were excluded. Consequently, only seven combinations were selected.

The PCR reaction mixture $(20 \mu \mathrm{L}$ total volume $)$ consisted of $20 \mathrm{ng}$ genomic DNA, $5 \mathrm{~mm}$ dNTPs, $50 \mathrm{~mm} \mathrm{MgCl}_{2}, 10 \mu \mathrm{M}$ of each primer, $5.2 \mu \mathrm{L} 10 \mathrm{X}$ Taq buffer, and four units of Taq polymerase. Samples were subjected to the following thermal profile: 5 min of denaturing at $94{ }^{\circ} \mathrm{C}$ and five cycles of three steps: $1 \mathrm{~min}$ of denaturing at $94{ }^{\circ} \mathrm{C}, 1 \mathrm{~min}$ of annealing at $35^{\circ} \mathrm{C}$, and 1 min of elongation at $72{ }^{\circ} \mathrm{C}$; for the next 35 cycles, annealing temperature was elevated to $50{ }^{\circ} \mathrm{C}$ ending with a elongation step of $10 \mathrm{~min}$ at $72{ }^{\circ} \mathrm{C}$. Separation of the amplified fragments was performed on $6 \%(\mathrm{w} / \mathrm{v})$ polyacrylamide gels. Gels were $0.15 \mathrm{~mm}$ in thickness and $34 \times 50 \mathrm{~cm}$ in dimension. Electrophoresis conditions were held at $75 \mathrm{~W}$ for $3 \mathrm{~h} 30 \mathrm{~min}$ at room temperature. The gels were stained with $\mathrm{AgNO}_{3}$. SRAP fragments were visually scored as present (1) or absent (0).

Euclidean distances for the morphologic traits were calculated among genotypes. For SRAP analysis, genetic distances were calculated according to standardized Jaccard's distance index (JDI). Both matrices were subjected to cluster analysis, one dendrogram was created for morphologic traits and another was made for the molecular data using in both cases the Ward's method for InfoStat statistical software (Di Renzo et al., 2001). Bootstrap analysis was performed using the WinBoot program (Yap and Nelson, 1996) with 2000 repetitive sampling of the SRAP data to compute bootstrap $P$ values.

\section{Results and Discussion}

Morphologic CHARACTERIZATION. Cluster analysis for morphologic traits showed three main clusters or groups (Fig. 1). Discriminating values were obtained for all of the evaluated traits, except capitulum color. Those traits involved with capitulum size showed the highest discriminating values. Similar results in artichoke were found by Porceddu et al. (1976) who evaluated the variability for 27 characters and by Elia and Miccolis (1996) when they evaluated 104 accessions using 11 morphologic traits and obtained five main clusters.

In the present analysis, cluster 1 included all the genotypes of $C$. cardunculus var. sylvestris and all genotypes of C. cardunculus var. cardunculus. Genotypes included in this group have taller plants than the artichoke cultivars used in this experiment but no differences in plant diameter were observed (Table 2). These genotypes have a greater number of capitula but smaller size than the artichoke group. Only spiny forms were observed among wild cardoon accessions. In contrast, spiny together with spineless forms were found in cultivated genotypes. The presence/absence of spines appears to be a key to understanding the origin of the genotypes at present in

Table 1. List of Cynara cardunculus cultivars analyzed in this assay and their origins.

\begin{tabular}{|c|c|c|c|c|c|}
\hline & \multicolumn{2}{|c|}{ C. cardunculus var. scolymus } & \multicolumn{3}{|c|}{ C. cardunculus var. cardunculus } \\
\hline & Cultivar & Origin & & Cultivar & Origin \\
\hline 1 & Salanquet & France & 18 & Horticulturist 1 & Argentina \\
\hline 2 & Caribou & France & 19 & Florensa S.A. & Argentina \\
\hline 3 & $\begin{array}{l}\text { Violeta de Provenza } \\
\text { (entire leaves) }\end{array}$ & France & 20 & Semence S.A. & Argentina \\
\hline 4 & $\begin{array}{l}\text { Violeta de Provenza } \\
\text { (indented leaves) }\end{array}$ & France & 21 & Horticulturist 2 & Argentina \\
\hline 5 & Nato & Argentina & 22 & Horticulturist 3 & Argentina \\
\hline 6 & Imperial Star & U.S. & & & \\
\hline 7 & Francés & Italy & \multicolumn{3}{|c|}{ C. cardunculus var. sylvestris } \\
\hline 8 & Violetto Precocce & Italy & 23 & Buenos Aires & Argentina \\
\hline 9 & Feltrin Roxa & Brazil & 24 & Colonia & Uruguay \\
\hline 10 & Feltrin Verde & Brazil & 25 & Entre Ríos & Argentina \\
\hline 11 & Gauchito FCA & Argentina & 26 & Santa Fe & Argentina \\
\hline 12 & Gurí FCA & Argentina & & & \\
\hline 13 & Estrella del Sur FCA & Argentina & & & \\
\hline 14 & Oro Verde FCA & Argentina & & & \\
\hline 15 & Esmeralda FCA & Argentina & & & \\
\hline 16 & $53 \mathrm{~B}_{3}$ & Argentina & & & \\
\hline 17 & $51 A_{3}$ & Argentina & & & \\
\hline
\end{tabular}

J. Amer. Soc. Hort. ScI. 132(2):208-212. 2007. 


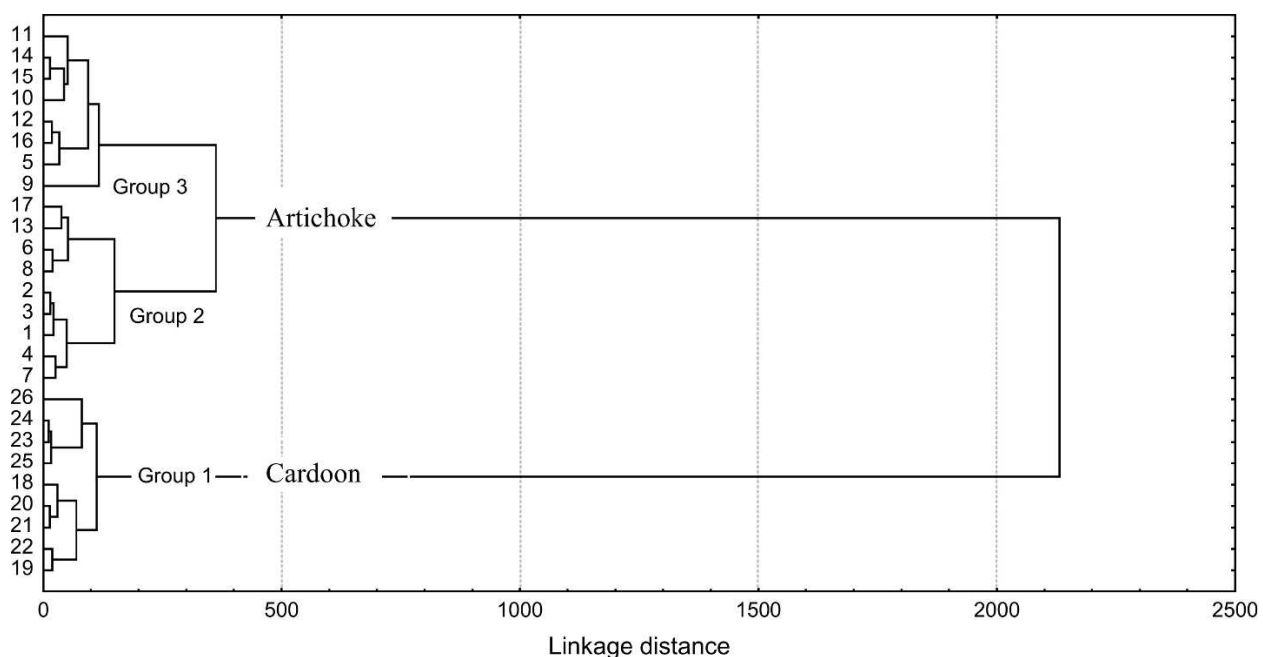

Fig. 1. Dendrogram compiled by Ward's method showing the grouping of 26 Cynara cardunculus accessions based on morphologic traits.

cultivation; Barbieri (1959) hypothesized that the spiny types were selected first and then the violet types, which possess less spiny capitula, and finally the nonspiny types.

Globe artichoke accessions were distributed into clusters 2 and 3. Cluster 2 included mainly French genotypes, whereas cluster 3 contained materials obtained in the local breeding program in which plants were selected for high numbers of capitula and big size.

Molecular CHARACTERization. Fifteen primer combinations were initially tested for amplification of globe artichoke genomic DNA. Eight of them showed inconsistent amplification or low polymorphism and were discarded. Hence, the analysis of the 26 globe artichoke and cardoon accessions was performed with seven primer combinations. Pejic et al. (1998) reported that 150 polymorphic bands make it possible for a researcher to reliably estimate genetic similarities among genotypes within the same species; we found a total of 275 polymorphic fragments (an average of 39 polymorphic bands per primer combination) ranging in size from 80 to 1200 base pairs. Several authors (Budak et al., 2004; Ferriol et al., 2004;
Li and Quiros, 2001) have reported the presence of 10 to 20 polymorphic bands per primer combination. The higher polymorphism rate found in this study could be the result of the use of polyacrylamide gels with superior height and width $(34 \times 50$ $\mathrm{cm})$ giving them a higher resolving power.

The data obtained from SRAP analysis was used to calculate JDI. Distances ranged from 0.30 (for the two 'Violeta de Provenza' accessions 3 and 4) to 0.87 (between accessions 8 and 3 ). Sonnante et al. (2002) analyzed 37 wild and cultivated artichoke genotypes with RAPDs and obtained JDI ranging between 0 and 0.31 . The highest distances values were obtained between $C$. cardunculus var. sylvestris accessions and cultivated globe artichoke genotypes. It was noted that a value of 0 was only obtained between two spiny cultivars collected from different regions of Italy. The homogeneity that was observed between these two cultivars could be because they are a single cultivar, which was named differently according to the region where they are cultivated. Similar results were found for Lanteri et al. (2004) who analyzed 118 accessions, including 89 cultivar types, with AFLP. They report that the wild cardoon accessions analyzed clustered together and showed an average genetic differentiation of $64 \%$ from the $C$. cardunculus cultivated forms; the cultivated cardoon accessions were also differentiated from artichoke accessions but with lower JDI, whereas artichoke accessions were separated into two main clusters.

The cluster analysis performed with this molecular characterization detected two main groups with bootstrap $P$ values above $75 \%$ (Fig. 2). One of them included only cultivated artichoke accessions $(P=81 \%)$ and the other comprised the wild and cultivated cardoons together with some artichoke cultivars $(P=68 \%)$.

Table 2. Mean values (MV) and standard deviation (SD) for the three clusters performed with all Cynara cardunculus genotypes considering morphologic data.

\begin{tabular}{|c|c|c|c|c|c|c|}
\hline & \multicolumn{2}{|c|}{ Cluster 1} & \multicolumn{2}{|c|}{ Cluster 2} & \multicolumn{2}{|c|}{ Cluster 3} \\
\hline & MV & SD & MV & SD & MV & SD \\
\hline Plant ht $(\mathrm{cm})$ & 107.36 & 15.09 & 58.47 & 8.88 & 86.43 & 23.20 \\
\hline Plant diam $(\mathrm{cm})$ & 167.12 & 15.10 & 134.68 & 14.78 & 164.19 & 15.58 \\
\hline Primary capitulum ht $(\mathrm{cm})$ & 4.84 & 0.92 & 9.57 & 1.07 & 9.20 & 0.66 \\
\hline Primary capitulum diam $(\mathrm{cm})$ & 4.96 & 0.90 & 8.51 & 0.79 & 9.61 & 0.49 \\
\hline Primary capitulum wt (g) & 52.67 & 30.80 & 225.46 & 26.85 & 276.79 & 13.60 \\
\hline Secondary capitula avg diam $(\mathrm{cm})$ & 4.39 & 0.00 & 7.16 & 0.48 & 8.26 & 0.43 \\
\hline Secondary capitula avg wt (g) & 38.96 & 0.95 & 135.25 & 1.37 & 176.46 & 0.39 \\
\hline Color $(1-3 \text { scale })^{\mathrm{z}}$ & 1.20 & 0.66 & 1.68 & 0.80 & 1.43 & 0.46 \\
\hline Spine $(1-2 \text { scale })^{\mathrm{y}}$ & 1.33 & 14.97 & 1.70 & 13.92 & 2.00 & 12.78 \\
\hline
\end{tabular}

${ }^{\mathrm{z}} 1=$ green, 2 = purple-green, 3 = purple.

${ }^{\mathrm{y}} 1=$ spine presence, $2=$ spine absence. 


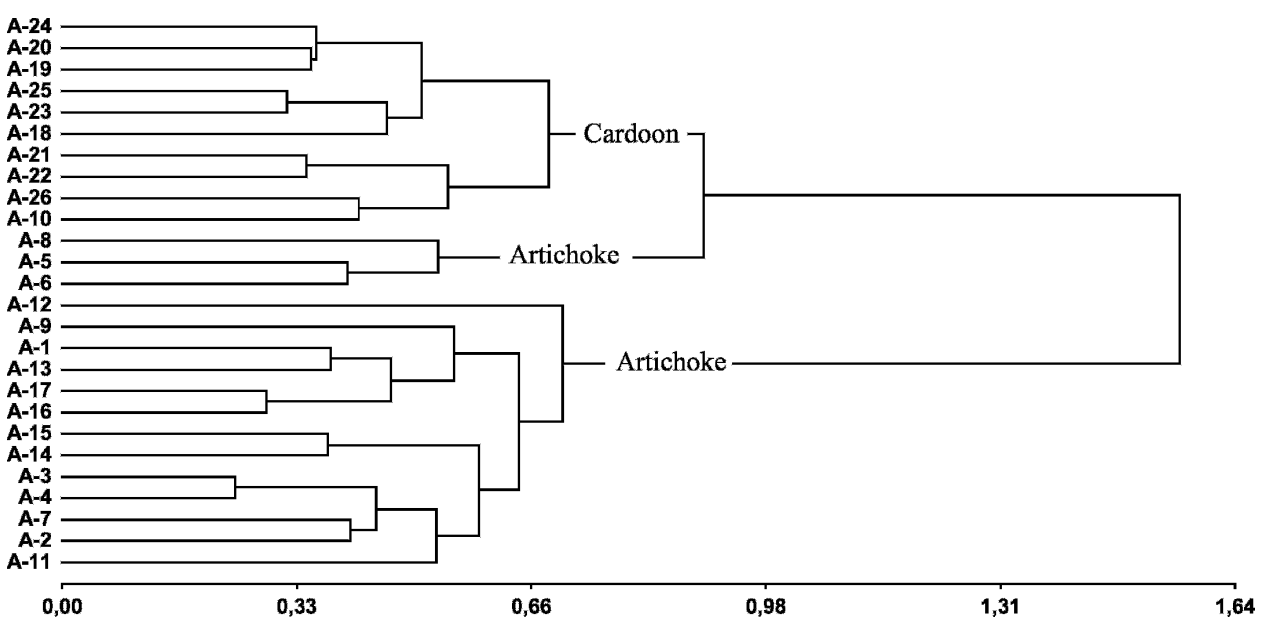

Fig. 2. Dendrogram compiled by Ward's method showing the grouping of 26 Cynara cardunculus accessions based on Jaccard's distances.

The tree node at JDI of 0.90 separates three artichoke cultivars from the cardoons $(P=47 \%)$. Only 'Feltrin Verde' remained in the cardoon group. The lowest JDI was between the two 'Violeta de Provenza' accessions $(P=99 \%)$. The close similarity was probably a result of a mutation in a single cultivar, which caused two distinct cultivars (one with entire leaves and the other with indented leaves). 'Violeta de Provenza' was propagated vegetatively, so simultaneous and indiscriminate propagation of the two types could have caused multiclonal composition of 'Violeta de Provenza' cultivars. The multiclonal composition in artichoke was also reported by De Vos (1986) for the American cultivar 'Green Globe' and by Tivang et al. (1996), who analyzed RAPD heterogeneity in two breeding populations of 'Green Globe' (genotypes not included in this study).

Morphologic traits produced better separations for artichokes than for cardoons. Although they have a common origin, they were exposed to different selection pressures. Although natural selection occurs in wild materials, human selection had a greater impact on cultivated varieties. Likewise, different objectives were proposed during domestication; cardoon was selected for its succulent leaves (Dellacecca, 1990), whereas artichoke was selected for high-quality capitula, possibly causing genetic divergence.

It must be noted that cardoon and artichoke genotypes are completely crosscompatible with fully fertile $F_{1}$ hybrids. Interspecific gene flow between closely related species may compromise the genetic integrity of botanical varieties. In consequence, the continuous molecular variation that was observed in this experiment could be the result of this fact. Acquadro et al. (2005) also reported continuous variation among $C$. cardunculus accessions. They found six exclusive SSR alleles in globe artichoke and 26 in wild cardoon, but no exclusive alleles were identified in cultivated cardoon. Indeed, globe artichoke and wild cardoon possess ribosomal genes of the same length (Maggini et al., 1988) that support the hypothesis that cardoon and globe artichoke have a common origin. Rottemberg and Zohary (2005) identify the wild forms of $C$. cardunculus as the wild progenitor stock of both cultivated forms.

However, despite this, cardoons and artichoke genotypes were positioned in different groups when SRAP markers were used. It is concluded from these results that SRAP could be a helpful tool to detect $C$. cardunculus genetic diversity and to classify accessions into groups based on their distance values.

\section{Literature Cited}

Acquadro, A., E. Portis, and S. Lanteri. 2003. Isolation of microsatellite loci in artichoke (Cynara cardunculus L. var. scolymus). Mol. Ecol. Notes 3:37-39.

Acquadro, A., E. Portis, D. Lee, P. Donini, and S. Lanteri. 2005. Development and characterization of microsatellite markers in Cynara cardunculus L. Genome 48:217-225.

Asprelli, P., V. Cravero, and E. Cointry. 2001. Evaluación de la variabilidad presente en una población de clones de alcaucil (Cynara scolymus L.). Revista de Investigaciones de las Facultad de Ciencias Agrarias 1:27-38.

Barbieri, R. 1959. Osservazioni sulla biologia del carciofo 'Spinoso Sardo' (Cynara cardunculus L. var. scolymus L.). Studi di Sassari Annali Facoltà di Agraria, p. 19-36.

Budak, H., R.C. Shearman, I. Parmaksiz, R.E. Gaussoin, T.P. Riosdan, and I. Dweikat. 2004. Molecular characterization of buffalograss germplasm using sequence-related amplified polymorphism markers. Theor. Appl. Genet. 108:328-334.

De Vos, N.E. 1986. Yield improvement through single-plant selection in globe artichoke (Cynara scolymus L.) 'Green Globe'. HortScience 21:662 (abstr).

Dellacecca, V. 1990. Cardo (Cynara cardunculus L.), p. 252-258. In: V.V. Bianco and F. Pimpini (eds). Orticoltura. Patron Editore, Bologna. Dellacecca, V., V. Magnifico, V. Marzi, E. Porceddu, and G.T. Mugnozza. 1976. Contributo alla conoscenza delle varietà di carciofo coltivate nel mondo. Atti $2^{\circ}$ Congresso Internazionale di Studi sul carciofo. Edizioni Minerva Medica, Turin, Italy, pp. 199-315.

Di Renzo, J., M. Balzarini, F. Casanoves, L. Gonzalez, M. Tablada, W. Guzmán, and C. Robledo. 2001. InfoStat. Estadística y Biometría. Versión 1.0. Facultad de Ciencias Agropecuarias, Universidad Nacional de Córdoba, Argentina.

Elia, A. and V. Miccolis. 1996. Relationship among 104 artichoke (Cynara scolymus L.) accessions using cluster analysis. Adv. Hort. Sci. 10:158-162.

Ferriol, M., B. Pico, P. Fernandez de Córdova, and F. Nuez. 2004. Molecular diversity of a germplasm collection of squash (Cucurbita moschata) determined by SRAP and AFLP markers. Crop Sci. 44:653-664.

Karaca, M., S. Saha, A. Zipf, J.N. Jenkins, and D.J. Lang. 2002. Genetic diversity among forage bermudagrass (Cynodon spp): Evidence from chloroplast and nuclear DNA fingerprinting. Crop Sci. 42:2118-2127.

Lanteri, S., I. Di Leo, L. Ledda, M.G. Mameli, and E. Portis. 2001. RAPD variation within and among populations of globe artichoke (Cynara scolymus L.), cv. 'Spinoso Sardo'. Plant Breed. 120: 243-247.

Lanteri, S., E. Saba, M. Cadinu, G.M. Mallica, L. Baghino, and E. Portis. 2004. Amplified fragment length polymorphism for genetic diversity assessment in globe artichoke. Theor. Appl. Genet. 108: $1534-1544$.

Li, G. and C. Quiros. 2001. Sequence-related amplified polymorphism (SRAP), a new marker system based on a simple PCR reaction: Its application to mapping and gene tagging in Brassica. Theor. Appl. Genet. 103:455-461.

Maggini, D.H., G.F. Tucci, and M.T. Gelati. 1988. Ribosomal RNA genes in species of Cynareae tribe (Compositae) II. Protoplasma 144:125-131. 
Miccolis, V., V.V. Bianco, A. Elia, P. Perrino, and N. Volpe. 1989. Valutazione della collezione Mediterranea di carciofo allevata nella valle dell' Ofanto. L'Informatore Agrario 45:35-41.

Pagnotta, M.A., M.T. Carderelli, N.A. Rey Muñoz, M. Tucci, and F. Saccardo. 2004. Assessment of genetic variation in artichoke of 'Romanesco' type by molecular markers. Acta Hort. 660: 99-104.

Pejic, I., P. Ajmone-Marsan, M. Morgante, V. Kozumplick, P. Castiglioni, G. Taramino, and M. Motto. 1998. Comparative analysis of genetic similarity among maize inbred lines detected by RFLPs, RAPDs, SSRs and AFLPs. Theor. Appl. Genet. 97:1248-1255.

Porceddu, E., V. Dellacecca, and V.V. Bianco. 1976. Classificazione numerica di cultivar di carciofo. Atti $2^{\circ}$ Congresso Internazionale di Studi sul carciofo. Edizioni Minerva Medica, Turin, Italy, pp. 1105-1119.

Roodt, R., J.J. Spies, and T. Burger. 2002. Preliminary DNA fingerprinting of the turfgrass Cynodon dactylon (Poaceae: Cloridoideae). Bothalia 32:117-122.

Rottemberg, A. and D. Zohary. 2005. Wild genetic resources of cultivated artichoke. Acta Hort. 681:307-313.

Rottemberg, A., D. Zohary, and E. Nevo. 1996. Isozyme relationships. Genet. Resour. Crop Evol. 43:59-62.
Sonnante, G., A. De Paolis, V. Lattanzio, and P. Perrino. 2002. Genetic variation in wild and cultivated artichoke revealed by RAPD markers. Genet. Resour. Crop Evol. 49:247-252.

Tivang, J., P. Skroch, J. Nienhuis, and N. De Vos. 1996. Randomly amplified polymorphic DNA (RAPD) variation among and within artichoke (Cynara scolymus L.) cultivars and breeding populations. J. Amer. Hort. Sci. 121:783-788.

Vos, P., R. Hogers, M. Bleeker, M. Reijans, T. van de Lee, M. Hornes, A. Frijters, J. Pot, J. Peleman, M. Kniper, and M. Zabeau. 1995. AFLP: A new technique for DNA fingerprinting. Nucleic Acids Res. 23:4407-4414.

Welsh, J. and M. McClelland. 1990. Fingerprinting genomes using PCR with arbitrary primers. Nucleic Acids Res. 18:7213-7218.

Wiklund, A. 1992. The genus Cynara L. (Asteraceae-Cardueae). Bot. J. Linn. Soc. 109:75-123.

Yap, I.V. and R.J. Nelson. 1996. WinBoot: A program for performing bootstrap analysis of binary data to determine the confidence limits of UPGMA-based dendrograms. Discussion paper series 14. International Rice Research Institute, Manila, Phillipines.

Zhang, L., P. Ozias-Akins, G. Kochert, S. Kresovitch, R. Dean, and W. Hanna. 1999. Differentiation of bermudagrass (Cynodon spp.) genotypes by AFLP analysis. Theor. Appl. Genet. 98: 895-902. 